University of Nebraska - Lincoln

DigitalCommons@University of Nebraska - Lincoln

8-2008

\title{
A Strategy for Third-Party Logistics Systems: A Case Analysis Using the Blue Ocean Strategy
}

Changsu Kim

Yeongnam University, Korea, c.kim@yumail.ac.kr

Kyung Hoon Yang

University of Wisconsin-La Crosse, kyang@uwlax.edu

Jaekyung Kim

University of Nebraska - Lincoln, jkim6@unl.edu

Follow this and additional works at: https://digitalcommons.unl.edu/managementfacpub

Part of the Management Sciences and Quantitative Methods Commons

Kim, Changsu; Hoon Yang, Kyung; and Kim, Jaekyung, "A Strategy for Third-Party Logistics Systems: A Case Analysis Using the Blue Ocean Strategy" (2008). Management Department Faculty Publications. 4. https://digitalcommons.unl.edu/managementfacpub/4

This Article is brought to you for free and open access by the Management Department at DigitalCommons@University of Nebraska - Lincoln. It has been accepted for inclusion in Management Department Faculty Publications by an authorized administrator of DigitalCommons@University of Nebraska - Lincoln. 
Published in Omega 36:4 (August 2008), pp. 522-534; Special Issue on Logistics: New Perspectives and Challenges; doi 10.1016/j.omega.2006.11.011 Guest Editors - Angappa Gunasekaran and T.C. Edwin Cheng.

Copyright @ 2007 Elsevier Ltd. Used by permission. http:// www.sciencedirect.com/science/journal/03050483

Submitted May 31, 2006; accepted November 11, 2006; published online May 24, 2007.

\title{
A Strategy for Third-Party Logistics Systems: A Case Analysis Using the Blue Ocean Strategy
}

\author{
Changsu Kim, ${ }^{a}$ Kyung Hoon Yang, ${ }^{\text {b }}$ and Jaekyung Kim ${ }^{c}$ \\ a School of Management, Yeongnam University, Korea; c.kim@yumail.ac.kr \\ ${ }^{b}$ Department of Information Systems, University of Wisconsin-La Crosse, \\ 233 Wing Technology Center, 1725 State Street, La Crosse, WI, USA; yang.kyun@uwlax.edu \\ c Department of Management, University of Nebraska-Lincoln, Lincoln, NE 68588-0491, USA; jkim6@unl.edu \\ Corresponding author- K. H. Yang, tel 608 785-5462, fax 608 785-5460
}

\begin{abstract}
One of today's most frequently discussed topics in the business world is how to escape from the intense Red Ocean and how to create an uncontested Blue Ocean. However, because there are few practical guidelines available on this topic, we will introduce a case study of a third-party logistics (3PL) provider, CJ-Global Logistics Service (CJ-GLS), to show how it aspires to be a leader in the newly introduced 3PL industry in South Korea. CJ-GLS is a latecomer in the logistics industry, and its resources, such as the number of trucks and warehouses, are relatively small in comparison to those of established companies. But, it has achieved a distinct competitive advantage through innovative information technology (i.e., RFIDradio frequency identification), which has enabled it to create an uncontested market space, electronic logistics business. One remarkable fact about CJ-GLS is that its swift growth comes not from attracting competitors' customers from the existing Red Ocean market but from creating a Blue Ocean market (3PL market), which previously existing incumbents ignored, and also from constructing a new business model founded on a RFID-based, ubiquitous-oriented 3PL system. Analyzed through a Four Actions Framework and characterized as Blue Ocean, this case study provides valuable information on how a company reinforces its competitive advantage from the Red Ocean while it transitions into a Blue Ocean by utilizing advanced information communication technologies.
\end{abstract}

Keywords: Case study, information systems, Blue Ocean strategy, third-party logistics, RFID, radio frequency identification

\section{Introduction}

Historically, a dominant business strategy has been competition among companies based on how to gain the largest share of market space. However, intense competition has caused industry to be oversupplied, and increased market share does not always lead to increases in profit. Under the circumstances, a fast follower strategy is hardly effective, and a new growth engine is seldom found. The Blue Ocean strategy is "a consistent pattern of strategic thinking behind the creation of new markets and industries where demand is created rather than fought for and the rule of competition is irrelevant" [1]. Therefore, the Blue Ocean strategy provides companies with guidelines on how to escape from intense competition over the same market space-where there are limited customers with an increasing number of competitors-by creating a new market space where there is less competition if any. 
Systematic and efficient logistics service has become one of the core support services of e-businesses, and many innovative strategies have been proposed $[2,3]$. Globally expanding Internet and e-businesses have brought new business models with less distribution layers resulting in customer-based logistics, Internet-based logistics, logistics for small-batch production [4], and zero-inventory logistics [5]. Companies who operated their own logistics network began to outsource part or all of their logistics function to the 3PL companies who provided expertise in solutions of logistic systems, transportation, warehousing, freight consolidation, distribution, inventory management, and logistics information systems $[6,7]$. Although 3PL itself is a relatively new business model $[8,9]$, several researchers have proposed newer business models for 3PL, such as the reverse logistics model [10] and grid computing technology services [11].

CJ-Global Logistics Service (CJ-GLS) is a latecomer in the Korean logistics industry, but it entered into the 3PL industry from the start and has the largest client bases in the market. The success of CJ-GLS comes from its market analysis capability, accurate customer requirement analysis, and the constructing capability of its logistics information systems (LIS). Ranked fourth in the Korean logistics industry, CJ-GLS successfully completed the development of ubiquitous LIS based on radio frequency identification (RFID) under the cooperation of ten systems development companies and research teams at three universities in South Korea.

By applying the Blue Ocean strategy to analyze CJGLS's business model, this paper provides valuable information on how a company reinforces its competitive advantage from the Red Ocean while it moves toward the Blue Ocean strategy by utilizing information technologies. For this case study, we interviewed the chief executive officer (CEO), chief information officer (CIO), CJ-GLS logistics strategy research manager, the team manager of the information strategy team, and several line workers in both July and September 2005.

The structure of this paper is as follows. In the following section, we describe the case company (CJGLS), including an explanation of CJ-GLS's information systems and its evolving path to e-business and $\mathrm{m}$-business supporting LIS. In section three, CJ-GLS's ubiquitous-oriented 3PL LIS, with its fundamental technology, RFID, is explained. Furthermore, we project the forthcoming new business model based on the ubiquitous-oriented 3PL LIS. In the fourth section, we introduce the framework of the analysis, the Blue Ocean strategy, and analyze the case using this framework. Problems and success factors found throughout the implementation of the ubiquitous-oriented 3PL LIS are stated. Finally, we summarize the CJ-GLS's strategic path and its capabilities in creating an uncontested Blue Ocean with its superb business processes and supporting technological capabilities.

\section{The first mover: CJ-GLS}

\subsection{Introduction to CJ-GLS ${ }^{1}$}

Starting its business as a subsidiary of Samsung Corporation in 1988, CJ-GLS adopted a cross-docking system in South Korea for the first time in its industry in 1991, built LIS in 1994, and introduced coastal shipping logistics in 1996. In 1998, the logistics systems and technology subsidiary unit of Samsung Corp. renamed itself CJ-GLS and launched its separation with an initial public offering of stock issued in 1998.

The core business units of CJ-GLS are 3PL service and domestic and international small parcel services, which are all based on corporate clients. 3PL service, the largest portion of its business, executes the logistics support for client companies and includes freight consolidation, distribution, transportation, warehousing, product marking, labeling, packing, and order management.

Clients of CJ-GLS are twofold: the first group are companies who have their own logistic systems but utilize CJ-GLS's superb 3PL and international small parcel service capabilities, and the second group are startups without their own logistics systems who utilize 3PL service for B2B (Business to Business) logistics service and small parcel services for B2C (Business to Consumer) logistics. Clients are composed of 220 companies from a variety of industries, including pharmaceutical, food, chemical, and e-marketplaces. Some of the international clients of CJ-GLS include Sony, National Panasonic, Lego, Nestle, and Osram Sylvania. Table 1 shows the growth of CJ-GLS's revenue. It increased from $\$ 138.6$ million in 2000 to $\$ 378$ million in 2004, which placed CJ-GLS in the top rank in 3PL service and the fourth rank in small parcel service. Figure 1 and Table 2 show Korea's market. ${ }^{2}$

\footnotetext{
1 Professor C. Kim advised the members of the project informally from time to time. He was with the project from the beginning and will also continue in this role for the next stage of the project.

2 In 2002, the total cost of Korean logistics was 85 million dollars. Of 66 million dollars of domestic logistics, $65.5 \%$ was selfowned and $34.5 \%$ were outsourced logistics operations.
} 
Table 1. CJ-GLS's sales revenue (unit: \$ million)

\begin{tabular}{lrrrrrr}
\hline Service Year & 2000 & 2001 & 2002 & 2003 & 2004 & $2005^{\mathrm{a}}$ \\
\hline Small parcel service & 18.2 & 58.9 & 111.2 & 132.4 & 139.3 & 154 \\
3PL & 120.4 & 132.2 & 158.6 & 201.3 & 238.7 & 295.5 \\
Total & 138.6 & 191.1 & 269.8 & 333.7 & 378.0 & 449.5 \\
\hline
\end{tabular}

${ }^{\mathrm{a}}$ Estimation.

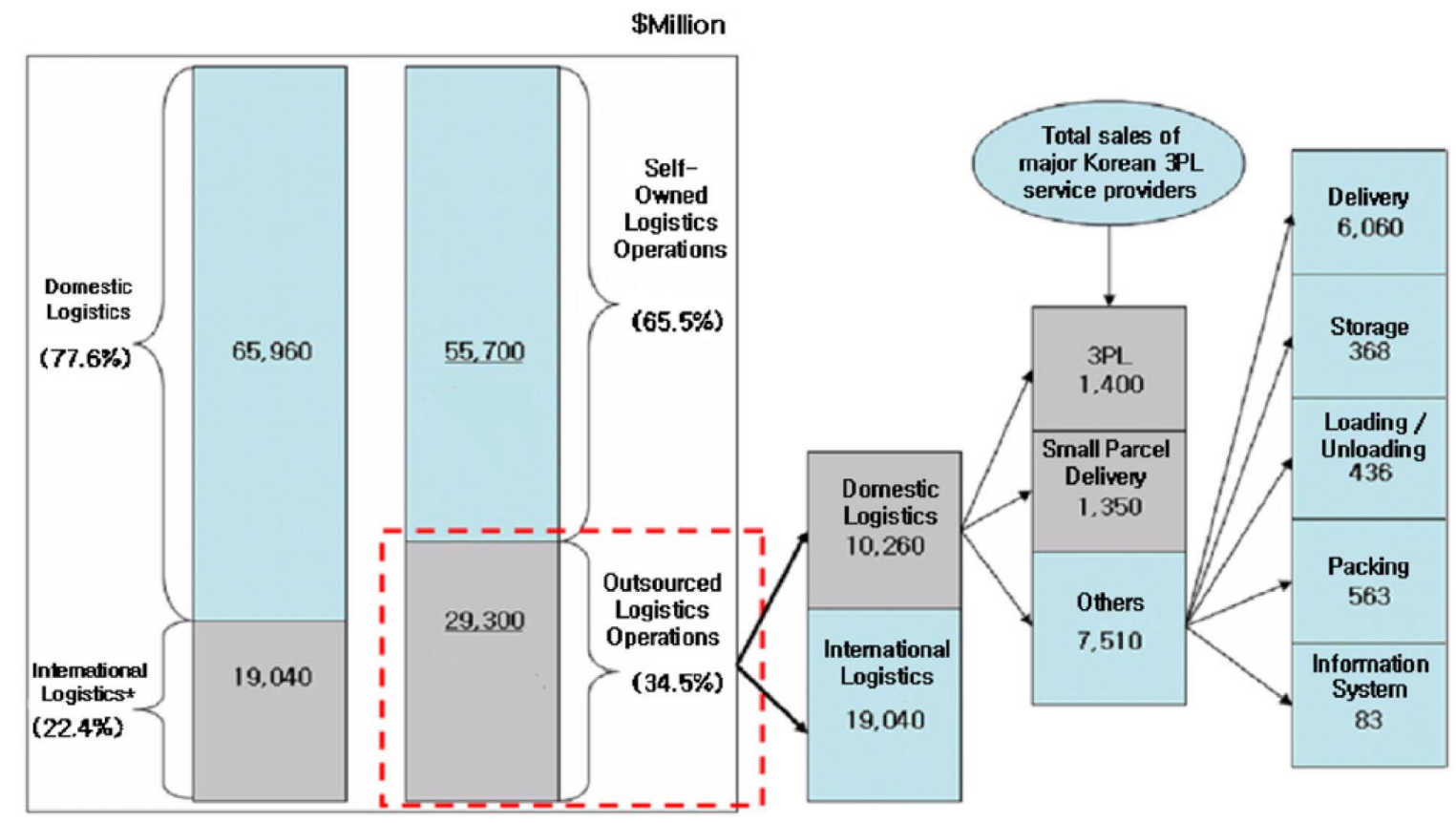

Figure 1. Korean logistics market.

* All costs incurred from international logistics are regarded as outsource logistics operations.

Table 2. Sales revenue of the major Korean logistics service providers in 2004

\begin{tabular}{lcccc}
\hline Company & Sales $(\$ \mathrm{Mil})$ & Growth rate $(\%)$ & Investment $(\$ \mathrm{Mil})$ & Growth rate $(\%)$ \\
\hline Daehan Tongwoon & 1100 & 0 & 55 & 0 \\
Hansol CSN & 380 & 18 & 5 & 10 \\
Hanjin & 680 & 11.1 & 64.2 & 9.3 \\
Hanjin Haewoon & 5625 & 6 & 250.8 & 71 \\
Hyundai Taekbae & 430 & 10 & 21.5 & 65.4 \\
CJ-GLS & 378 & 24 & 30 & 200 \\
KC-TC & 134.6 & 17 & N/A & N/A \\
\hline
\end{tabular}

\subsection{The logistics information systems of CJ-GLS}

Further sophisticated physical space utilization distinguishes the logistics industry from the manufacturing industry, where business operations are executed mainly in headquarters and manufacturing facilities. However, logistics operations are executed in a multidimensional physical space comprised of headquarters, warehouses, carriers, and clients. As the mobility of operation execution becomes an important factor in logistics services [12], LIS in CJ-GLS has evolved from e-business supporting LIS, to $\mathrm{m}$ business supporting LIS, to the ubiquitous computing-oriented LIS. Figure 2 shows the progress of CJGLS LIS development. 


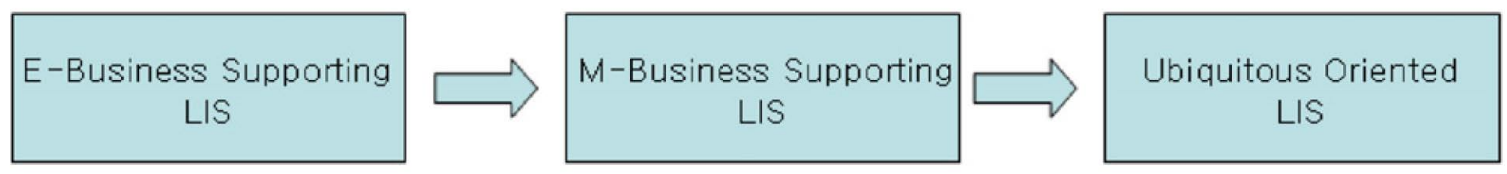

Figure 2. Evolution of CJ-GLS's LIS.

CJ-GLS learned a lesson from the failures of other Korean logistics service providers who adapted foreign solutions without thorough fit tests between their business processes and the system. To avoid such mistakes, CJ-GLS followed an in-house development approach for their information systems through its sister company, CJ Systems. The effort to understand field operations reduced the erroneous design causing conflicts between the actual business processes and the information flow, thus leading to an improved quality of IS. Stemming from knowledge of LIS development, CJ-GLS even commercialized the NELS-Series (a Korean logistics operations solution) and provided consulting services on LIS design and implementation.

\subsubsection{Fundamental logistics information systems: OMS, TPS, and WMS}

From its early stage of market entrance, CJ-GLS concentrated on its resources and capabilities in order to increase its competencies in 3PL industry by building business operation systems targeted to 3PL processes. These are composed of order management systems (OMS), warehouse management systems (WMS), and transport management systems (TMS). OMS is constructed based on the business process regarding client's order management, such as assigning and placing orders into appropriate subsystems. Its main functions are order receipt, order tracking, performance analysis, and the generation of ad hoc reports. Ordered materials are shipped from warehouses and delivered to the client's agents or distribution centers. Linked to OMS and TMS, the main function of WMS is inventory management through tracking the movements of products, the storing of materials within a warehouse, sharing accurate inventory information with the clients, and directing the movement of goods based on urgency for space, equipment, inventory, and personnel. TMS is connected to and shares information with WMS and OMS for accurate delivery of ordered materials. The main function of TMS is invoice management, freight tracking, and dispatch management.

\subsubsection{E-business supporting logistics information systems}

Upon these three information systems, CJ-GLS implemented new e-business support features focusing on increasing business efficiency, reducing business process time, and improving ease of use. First, the storefront, a web-based user interface, was developed to allow clients and other IS users to access the system through the Internet. Delivery routing systems powered by artificial intelligence-supported technology were added to TMS for safe and on time delivery. OMS is connected to the finance and accounting modules of SAP's enterprise resource planning systems. Data generated from WMS and TMS are analyzed with a data mining technology and applied to customer relationship management (CRM) systems for managing uncertainties such as preorder forecasts and delivery routing adjustments.

\subsubsection{Mobile-business (M-Business) supporting logistics information systems}

As a first step for ubiquitous computing-oriented LIS, CJ-GLS added mobility to its e-business-based LIS, specifically to TMS. A core strategy of TMS mobilization is threefold: (1) to enable clients and CJGLS to track the shipments in and out of warehouses or distribution centers, (2) to enable clients and CJGLS to predict the accurate arrival time of the shipments, and (3) to reflect the arrival information of delivery scheduling in order to increase the efficiency of the system. TMS provides schedules locally and nationwide, and it sends the scheduling information to the carriers' personal digital assistant (PDA). Carriers download the shipping schedules from TMS, and the shipping status is administered back into TMS through a global positioning system (GPS). This mobile technology-based logistics management enables not only clients to access shipping status and scheduling information through the storefront using their web browsers but also the provider to manage issues in shipping.

Although the mobilization of OMS and TMS improved the efficiency of order- and freight-related business processes, the data managed through WMS are less developed as manageable information despite the relatively narrow scope of coverage compared to order management and transport management within all of LIS. The major automation of warehouse management processes is based on a bar code system where warehouse operators check inventories using the bar code readers one by one and information from 
the readers is sent to WMS. The inefficiency of the bar code-based WMS comes from reading errors, such as redundant or omitted readings, and higher payroll costs for the operators.

To improve the warehouse business process and maximize efficiency and synergy from the integration of three LIS subsystems, the information strategy team reengineered the business processes beginning with the inventory in warehouse operations. Their analysis recommended a development and application of RFID technology, which enables automated total management by unifying the information on inventory, storage, and delivery into an attachable RFID chip.

\section{Toward a deep Blue Ocean: an ubiquitous-ori- ented 3PL system}

Although the mobilization of TMS increases customer satisfaction and efficiency, its coverage is limited to a part of the entire 3PL business process, resulting in low productivity gains as it is solely mobile technology utilization instead of an enterprise-wide business strategy promotion. Figure 3 describes the information flow in 3PL LIS.

As Carr [13] argued, competitive advantage driven by ICT (information and communication technology) is not sustainable unless the ICT strengthens the existing competitive advantage. Companies such as Han- jin and Hyundai, who entered into the 3PL market in 2000, also integrated their 3PL systems with their own IS and those of their clients (e.g., Hanjin's e-HaNex and Hyundai's HiTexII). The strategy CJ-GLS is presently using to gain a competitive advantage over the industry incumbents involves developing and applying a new ICT-driven LIS. This innovative approach is always accompanied by a great risk of failure, and if one of two aspects is not successful, whether it is the ICT or the application, it can result in a disastrous outcome for CJ-GLS.

To continue along a strategic path, there was a pressing demand for an ubiquitous-oriented 3PL system and new technological innovation. The core technology necessary to accomplish promoting the strategy for an ubiquitous computing 3PL system is RFID technology, which remotely recognizes large volumes of inventory and manages inventory information. A collaborative business model was developed to harmonize and coordinate all the business processes. The RFID-based ubiquitous 3PL system was promoted to apply a collaborative business model into the field operation of warehouses and distribution centers.

\subsection{RFI technology}

RFID uses radio frequency to transmit stored information to a remote reader. Its advantage over the bar code is noncontact based, where the operators do not need to scan directly from each individual bar code.

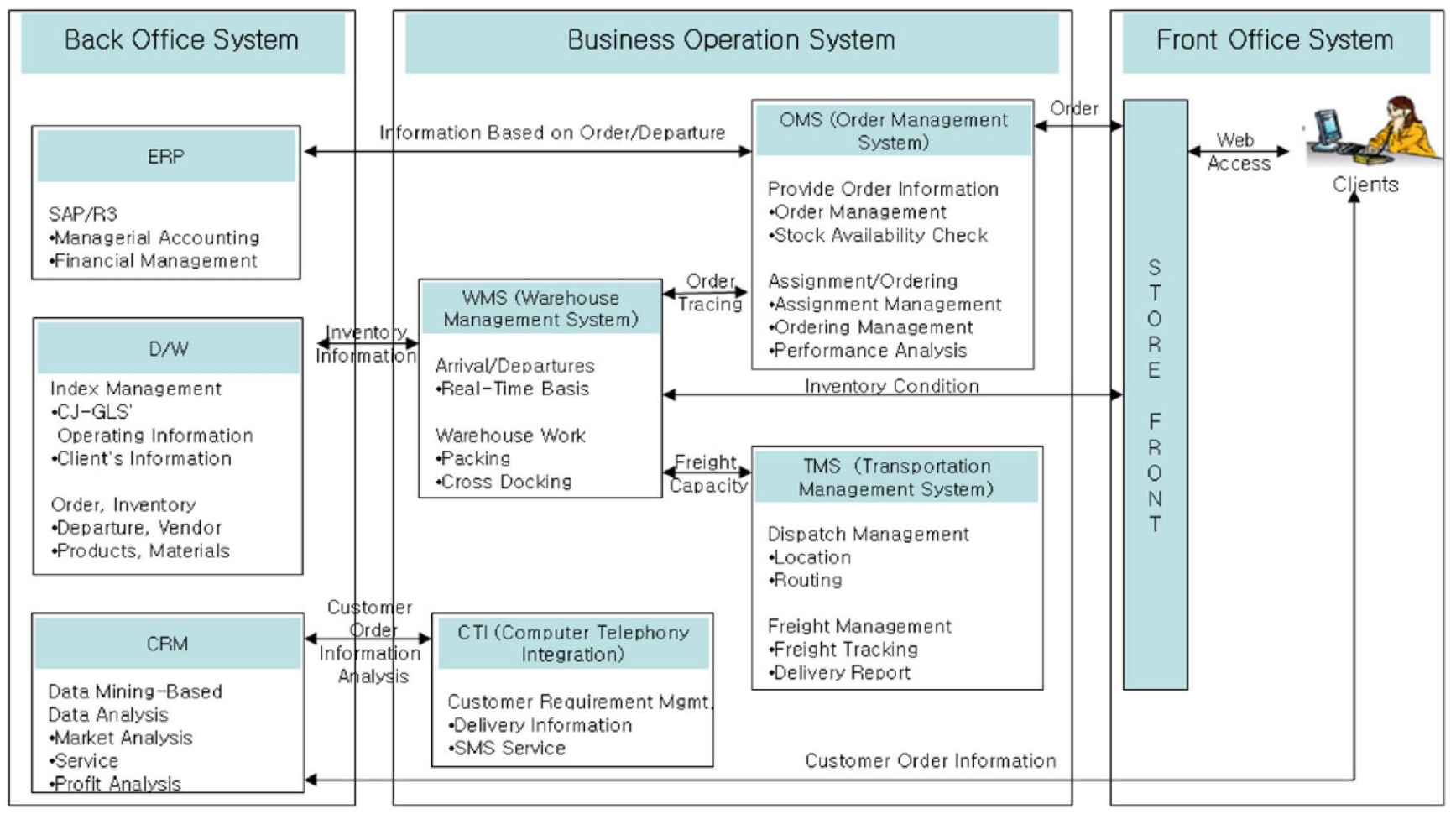

Figure 3. Information flow in CJ-GLS's 3PL LIS. 


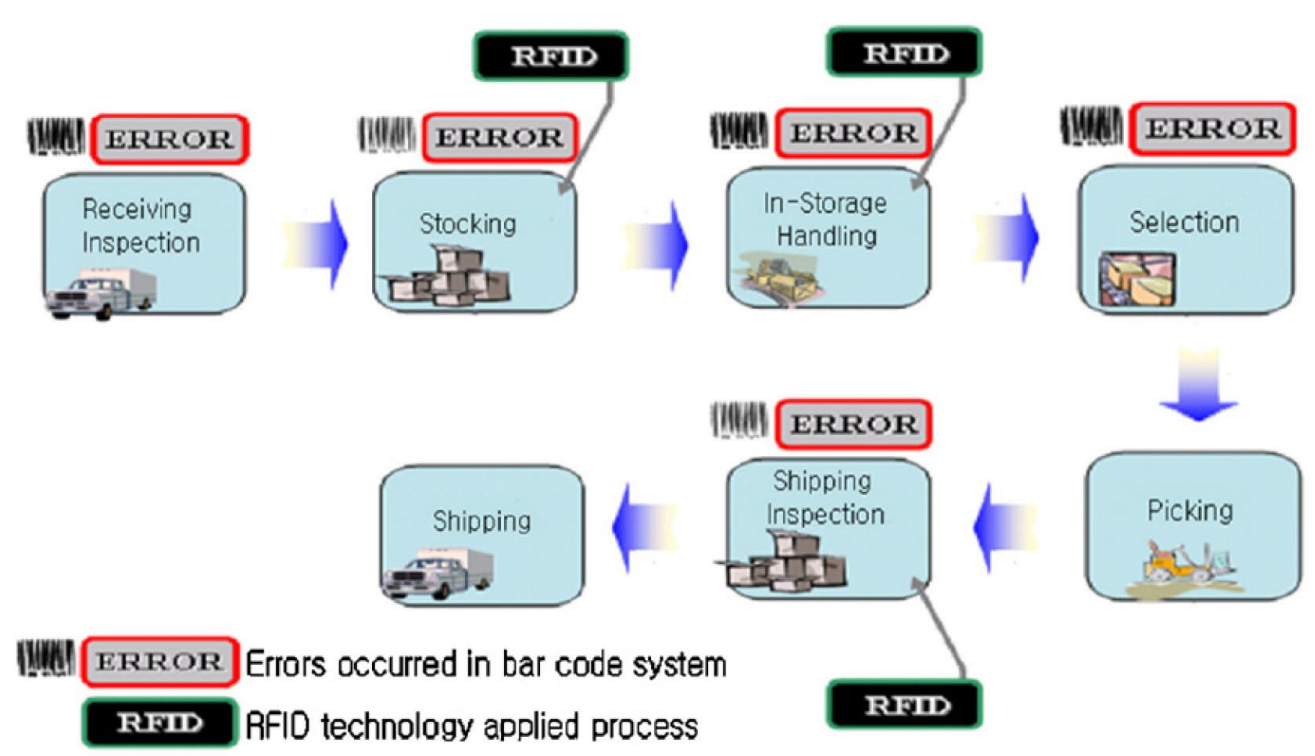

Figure 4. WMS process before RFID introduction.

Information about the material from the beginning of its production up to its distribution is stored in a RFID tag that is traceable through a $900 \mathrm{MHz}$ wireless frequency. In the bar code system, operators need to scan every single bar code with bar code readers in order to recover such information. The RFID system enables operators to retrieve the information on inventory at once regardless of its quantity. The storage capacity of RFID tags is about 6000 times larger than that of bar codes, which allows different IDs to be assigned to the same product and other variable information. While the bar code can only be read, the RFID allows rewriting updated information over previously recorded information. RFID is widely implemented in replacing bar code systems due to its capabilities. Several cases of successful RFID implementation are found in other areas, like museums [14], libraries [15], health care [16], and the construction industry [17]. The same advances make RFID the next exciting innovation in the logistics industry.

The standard RFID technology adopted by CJ-GLS for their WMS is the electronic product code (EPC) developed by MIT and used by Wal-Mart, Metro, the electronic toll collection system in Japan, baggage checking system at the San Francisco airport, the Technology Museum of Innovation in San Jose, and the Department of Defense to connect the global manufacturing and distribution industry.

In CJ-GLS, the starting point has been the replacement of the bar code system in warehouses and distribution centers with RFID tags. The information flow of warehouse business processes is composed of:

(1) Receiving inspection: materials are inspected before they get unloaded, and each bar code is scanned in order to be matched with the information in WMS.

(2) Stocking: unloaded materials are placed into storage space designated by WMS.

(3) In storage handling: material information, such as volume, weight, and storage requirements, is handled, and each time transfer occurs, the scanned bar code information is transferred to WMS.

(4) Selection: bar codes of ordered materials are received from WMS and matched by scanning each material.

(5) Picking: selected materials are staged for shipping.

(6) Shipping inspection: materials are inspected before they get loaded, and each bar code is scanned to be matched with information in WMS.

(7) Shipping: loaded equipment departs to the next destination when all requirements are met.

For each of these seven processes as shown in Figure 4, warehouse operators are required to scan bar codes of the materials continuously to check the inventory, both previous and additional, and to calculate what is missing. This frequent bar code reading causes many problems from scanning omissions, resulting in an inaccurate inventory and unclear boundary of liability between processes. These problems cause delays in all the business processes of LIS, including OMS and TMS.

RFID-based WMS reduced the seven-step warehouse processes into four (Figure 5). It enabled managing inventories on real-time basis tracking, as well as updating inventory information, which resulted in accurate inventory information. Along with WMS, accurate information minimized additional costs from 

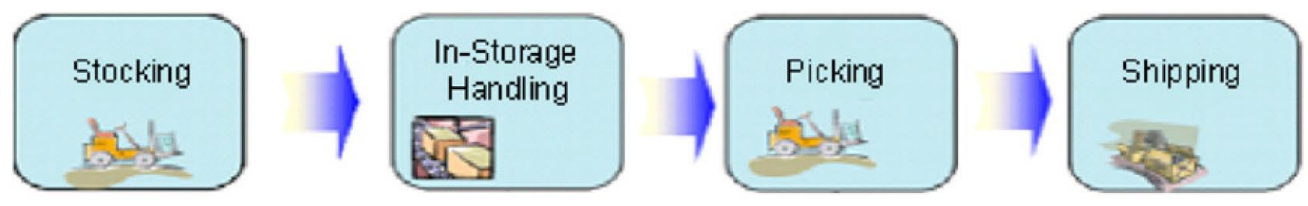

Figure 5. WMS process after RFID introduction.

returned materials. Overall, management innovation, work time reduction, optimized inventory, zero errors, and labor cost reduction were achieved.

The RFID-based WMS increased the accuracy of inventory management and cut down work time to one-third of the previous system. For example, receiving inspection time has been reduced from 10 to $3 \mathrm{~s}$, shipping inspection time has been reduced from 600 to $3 \mathrm{~s}$, and in-storage handling time has been reduced from 10 to $3 \mathrm{~s}$. As the amount of materials increase, inspection time in the bar code-based WMS increased in multiples of the amount, not including the added time due to errors and omissions. However, the inspection time in the RFID-based WMS was not influenced by the changes in the amount ordered and was free from added time caused by errors and omissions. These effects become clearer as the amount of inventory increases. Qualitative benefits include the operation of value-added service from the connection of existing information systems and RFID-based ICT innovation and its application into the collaborative business model, systematic knowledge acquisition through collaboration and knowledge-sharing among participants (universities and research institutions), and guiding the experience through the first application of RFID in logistics operations in South Korea. Figure 6 shows the details of the benefits CJ-GLS acquired from RFID- based WMS, and Table 3 shows the advantages and disadvantages of RFID.

\subsection{Future direction and a new business model}

\subsubsection{Future direction}

In 2004, CJ-GLS finished the connection of the RFID, ubiquitous-oriented TPS system into its WMS. Complete application to the entire core cooperating system is expected to be finished by late 2007 or early 2008. Once the application is finished, the LIS will be developed into the more advanced WMS, along with TMS and OMS. Protocols, scheduling modules, and security modules are under development. In OMS, the order management team recognizes the tag information provided from the manufacturing client, and the order will be processed based on this information. The mobilized TMS will evolve into an integrated ubiquitous computing system composed of a visibility management system (VMS) to solve routing problems [18], which is incorporated with the clients' IS; logistics management system (LMS), which manages the actual movement of inventory; and global delivery system (GDS), which manages international logistics. The main technology centered in the integrated system is RFID, which provides material information and delivery information from where the material is packaged, to warehouses, and to its final destination.

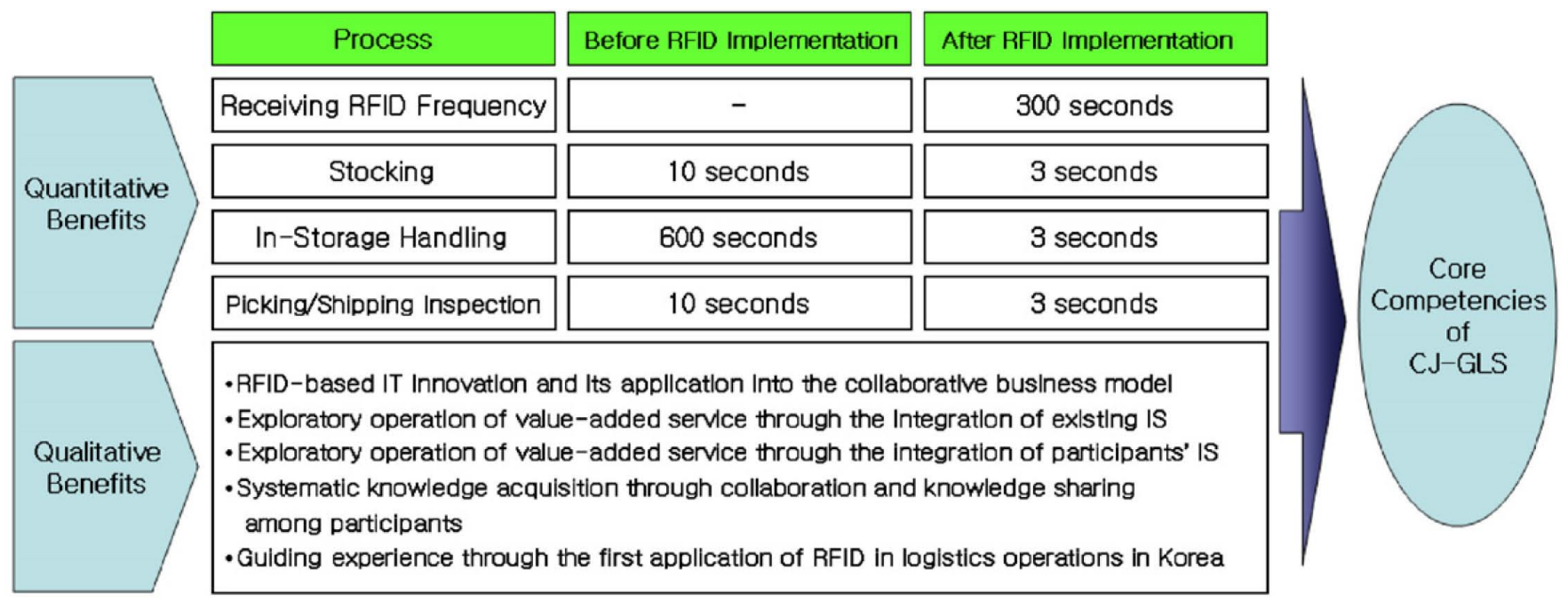

Figure 6. The effect of RFID-based WMS. 
Table 3. Advantages and disadvantages of RFID-based WMS

\begin{tabular}{|c|c|}
\hline Advantages & Disadvantages \\
\hline Reduction of number of processes & $\begin{array}{l}\text { Higher implementation cost and complexity } \\
\text { in developing RFID-based systems }\end{array}$ \\
\hline Accurate information from real-time basis tracking and updating & No proof of read on multiples \\
\hline Work time reduction (one-third) & Affected by metal and liquid \\
\hline Optimized inventory & Tag can be removed/lost \\
\hline Speeding up of entire logistics process & $\begin{array}{l}\text { No existence of internationally agreed fre- } \\
\text { quencies for RFID operation }\end{array}$ \\
\hline Pinpointing the error location and the reason & The lack of standards \\
\hline Reduced processing time & \\
\hline Minimization of stockpiles & \\
\hline Reduced manpower costs & \\
\hline Global linkage possible & \\
\hline
\end{tabular}

The final goal of the integration is the real-time enterprise system, which connects to the customer relationship management (CRM) system for better forecasting on customer orders and more accurate information. The data generated from the RFID tag will be useful input in solving other supply chain-related problems such as demand uncertainty [19], supply chain conflicts [20], reverse logistics of customer return [21], forecast errors [22], and route selection in transportation [23]. Figure 7 shows the schedule.

\subsubsection{New business model}

CJ-GLS's strategic movement includes the improvement of its internal IS with RFID technology, which strengthens its competitive position in the existing market (Red Ocean) and in the development of a new market called RFID-based electronic logistics business. CJ-GLS plans to develop a new business model based on an application service provider (APS) through utilizing its connection between the manufacturing industry and distribution industry.

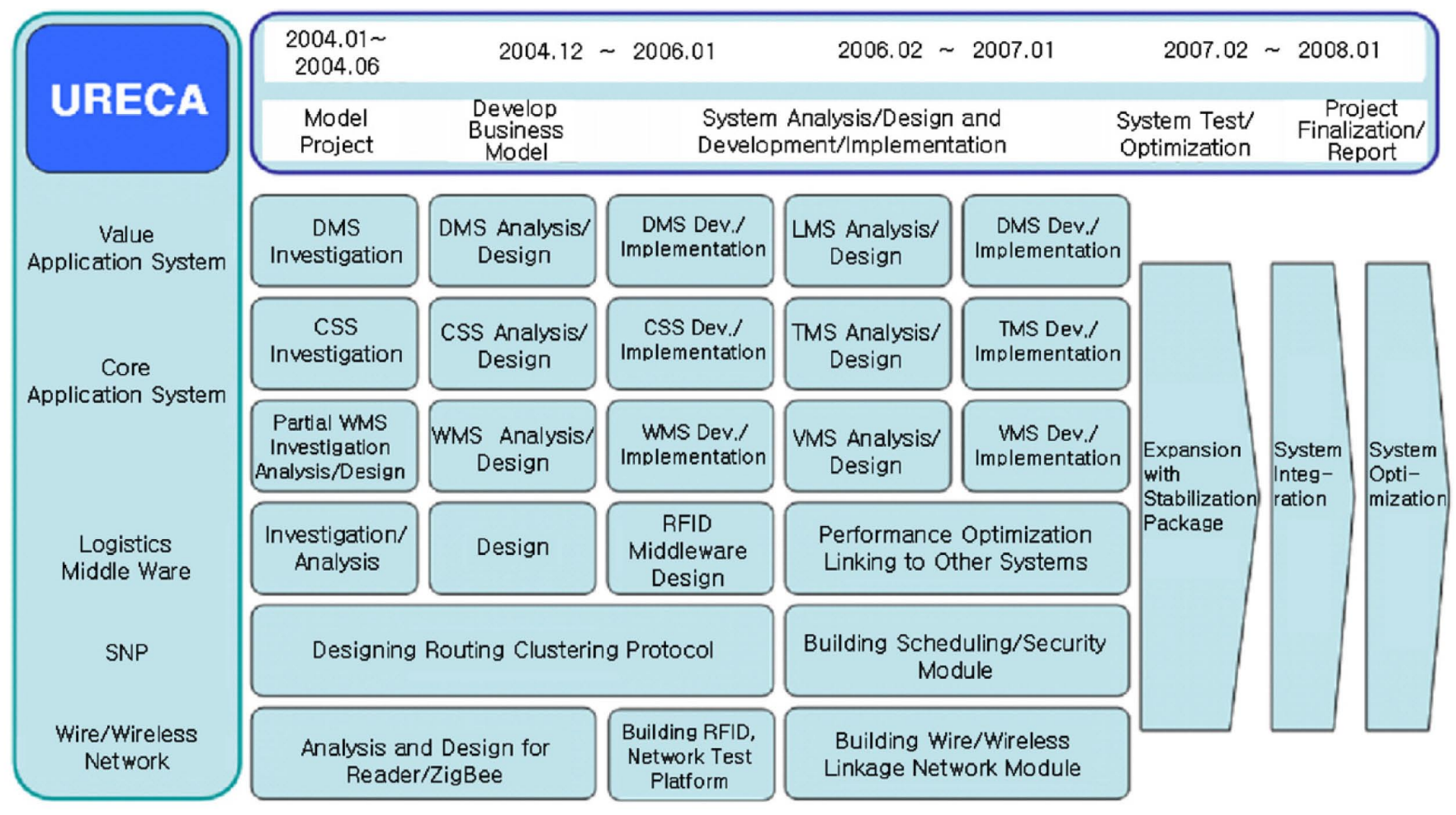

Figure 7. Project schedule for the RFID-based, ubiquitous-oriented 3PL system.

* URECA: The project name. 
Current major distribution companies like WalMart, Tesco, and Costco require major manufacturers to attach RFID tags on the products they want distributed through these distribution companies. Major manufacturers may be capable of doing this. However, small and medium enterprises (SMEs) could face technological difficulties and a considerable cost increase for doing this. In the evolving electronic logistics service market, CJ-GLS will provide solutions covering the entire logistics service from tag installation, to ONS registration of the clients' products, to product history management, and eventually to becoming a fourth-party logistics (4PL) service provider. 4PL increases the SMEs' opportunity for marketing their products to major distribution companies, provides efficiency in the logistics process, and allows them to concentrate on their core competencies. An ubiquitous electronic logistics business model will allow CJ-GLS to create an uncontested new market space where new demand and high growth is possible.

\section{Analysis of case}

\subsection{Framework of analysis: the Blue Ocean strategy}

There are two opposing market space concepts: the Red Ocean, which is the current existing industry, where boundaries and competitive rules are well known to competitors who try to achieve a greater share of existing demand, and the Blue Ocean, which is any new industry where "demand is created rather than fought over" [24]. The Blue Ocean strategy is the strategy which can avoid severe competition by creating an uncontested market space. Two approaches for creating a Blue Ocean have been proposed. The first approach is to create completely new industries (e.g., an online auction service in the auction industry). The other approach is to create a new niche market within the existing industry by altering the existing competitive rules (e.g., ubiquitous-oriented 3PL in the logistics industry). Kim and Mauborgne [24] suggested the Four Actions Framework, which provides guidelines to create a new strategy profile and which also defines the characteristics of a Blue Ocean strategy. Using these frameworks, we have identified CJ-GLS's electronic logistics business model as a case of a Blue Ocean strategy.

\subsection{Four Actions Framework for CJ-GLS's RFID service}

The ubiquitous electronic logistics business model of CJ-GLS is analyzed based on the Four Actions Framework of "Eliminate," "Reduce," "Raise," and
Table 4. ERRC chart of CJ-GLS

Eliminate

Errors caused by manual handling of warehousing activities

Errors in recognizing bar codes resulting from repetitive work

Work delays involving deliveries to or collections from warehouses

Raise

Automated handling rates of logistics activities Information service optimized for the company's activities

Speed of process

Reduce

Labor costs and fixed costs for warehouse management Inefficient work activities

Steps and errors

Create

Blue Ocean market of the electronic logistics business New cyber distribution/logistics

New customer satisfaction and loyalty

"Create" (ERRC) proposed by Kim and Mauborgne [1]. The results are summarized in Table 4.

First, the introduction of a RFID-based electronic logistics business has resulted in the "elimination" of certain elements that have been taken for granted in the industry, such as the occurrence of errors caused by manual handling of warehousing activities, errors in recognizing bar codes resulting from repetitive work, and work delays involving deliveries to or collections from warehouses. Secondly, the concerning elements that should be reduced below standards of the industry (namely, labor costs for warehouse management and fixed costs) have been reduced thanks to automation and optimized work handling, respectively. Such "elimination" and "reduction" of inefficient work activities have been effective in sharply cutting both time and costs. The third aspect concerns elements that have been "raised" higher than industry standards compared to rival companies, and they include increases in automated handling rates of logistics activities and in information service optimized for the company's activities. More specifically, large volumes of loaded cargo are recognized in warehouses within a short time, and information on cargo taken in or out of warehouses is delivered to the operation system in real time, thus enhancing efficiency in the entire logistics business and improving the information service. Finally, disproving the existing, generally ac- 
cepted notion that logistics companies only provide logistics-related services, CJ-GLS has successfully realized an ubiquitous-oriented, third-party logistics system based on RFID. This system has not yet been offered by other companies, thereby "creating" a Blue Ocean market for the electronic logistics business that is a new cyber distribution/logistics area where competition does not exist. Hence, CJ-GLS has created new customer satisfaction and loyalty by achieving accurate prediction and information on shipments due to the location information of carriers on a real-time basis, which has optimized delivery schedule and dispatch.

In summary, as can be seen from Table 4, we apply the Four Actions Framework to analyze the CJGLS ubiquitous-oriented electronic logistics model. CJ-GLS creates a Blue Ocean in terms of an electronic logistics business model, which is within their core businesses. CJ-GLS focuses on noncustomers, uncontested market space, and a new demand for the electronic logistics business. The case analysis of CJ-GLS provides analytic frameworks and useful insights for capturing the Blue Ocean opportunity.

\subsection{Comparison with the Red Ocean strategy}

In this section, CJ-GLS's strategy is compared to that of the competitor's in view of the Blue Ocean strategy.

\subsubsection{Market space}

Other logistics service providers tried to compete in existing market space, the Red Ocean, but CJGLS explored uncontested market space using the RFID tag agency service. The new, uncontested market space that CJ-GLS's new business model will create expands from the existing 3PL industry, with new RFID-enabled services. In addition to the fulfillment of existing 3PL service, these services include the assignment of unique EPC to physical RFID tags and their attachment to the manufacturers' products.

\subsubsection{Competition}

Other Korean logistics service providers tried to attract more market share from the existing competition based on accurate and timely delivery of products at the lowest freight cost. CJ-GLS made the competition irrelevant. While the incumbents have deployed more physical distributions with the new RFID outsourcing service, CJ-GLS adds more value to the clients, along with providing more advanced service in the physical delivery of the product. This additional value to the clients makes the competition based on physical delivery irrelevant.

\subsubsection{Demand}

The Red Ocean strategy exploits existing demand, while the Blue Ocean strategy creates and captures new demand. Other competitors try to raise demand in the current existing market, but CJ-GLS creates new demand using RFID. Even though RFID was new technology that other companies had not tried, CJ-GLS took a risk creating a new market.

\subsubsection{Value/cost trade-off}

The Red Ocean strategy emphasizes the current model of trade-off between value and cost, while the Blue Ocean strategy looks at value and cost in a new way. Incumbents try to add value by increasing the additional cost of physical resources, such as storage and trucks. But the Blue Ocean strategy tries to remove human errors. Removing human errors in inventory management using WMS, as well as OMS and TMS, brings additional value to clients instead of incurring the additional cost of physical resources.

\subsubsection{Alignment of the system}

The Red Ocean strategy aligns the whole system of a firm's activities with its strategic choice of differentiation and low cost, while the Blue Ocean strategy aligns the whole system of a firm's activities in pursuit of differentiation and low cost. CJ-GLS's RFID service, in addition to the current 3PL service, brings exclusive values to clients. To achieve this, CJ-GLS analyzed and redesigned its internal business process and educated its employees. Integrating the two services brings synergy to clients, such as convenience from one-stop service and efficiency from concentrating on clients' core business.

\subsection{Findings: problems and success factors}

During implementation of the new technologies into existing IS and business processes, several organizational and technological problems are bound to occur. To solve such problems, CJ-GLS involved all levels of its employees in searching out solutions and effective alternatives. After surveying possible solutions and/or alternatives, the information strategy team conducted several strategic seminars to establish an efficient development direction to solve problems. In this section, we list the bottlenecks and success factors that we faced in building the Blue Ocean strategy.

\subsubsection{Bottlenecks}

Bottlenecks, whether they are social-oriented or technology-oriented, are common when new technology is introduced into an existing business process and organizational structure. 
4.4.1.1. From the organizational perspective. CJ-GLS experienced two problems from the mobilization of TMS. The carrier's equipment operators complained about the delivery schedule downloaded to their PDAs from TMS, considering it an invasion of privacy. The operators also argued that the impracticality of the schedule created from freight information, distance between customers, and the expected delivery time is a result of the lack of actual work experience. The vehicle location tracking system, enabled by GPS or geographic information systems (GIS), which provides real-time tracking for clients, was also considered an infringement on the operators' privacy.

Another difficulty arose when the RFID technology was implemented to WMS. Warehouse operators felt that RFID would eventually replace their jobs. This was the source of their uncooperative attitudes. For the scheduling problem, CJ-GLS upgraded their routing engine to include additional fixed and variable unloading time. GPS and GIS replaced the geolocation service to improve the accuracy of vehicle locations. Continuous education and learning resolved the issues of privacy invasion and the possibility of job lost from adopting the technology. Workers were assured that the new system was implemented to increase customer value and accurate delivery and was for the common benefit of all.

\subsubsection{From the technological perspective. The biggest} concern at CJ-GLS was having no prior experience in RFID technology and the fact that there were no practical cases of its successful application. The absence of a technology standard, a successful application case, and a shortage of insight on the forthcoming business process changes were the main shortfalls. All of these implied a high possibility of failure when using a RFID-based 3PL system.

The major technical problems of RFID utilization in a warehouse setting are multiple readings and omission errors. As freight with RFID tags is being processed at one of the steps of the warehouse operation, the designated RFID antenna for the step should automatically receive the information of the freight being processed, and this information should be transferred to WMS to show where and at which step of the operation the freight is. However, multiple receiving by non-designated antennas or antennas designated for other steps of warehouse operation misleads WMS to recognize the freight to be at multiple steps at the same time. Multiple receiving occurs due to the interference of noise and obstacles in the warehouse and multidirectional frequencies sent by RFID tags.
Multiple receiving errors were corrected by reprogramming the middleware that processes information received by RFID antennas. The middleware allowed WMS to recognize information sent by the RFID antenna designated for the second step only when the information from the antenna designated for the first step had been entered and so forth with the rest of the steps.

Another technical bottleneck occurs when the RFID antenna fails to receive freight information sent by RFID tags. Such failures are caused when the frequencies from the RFID tags are weakened or blocked by the stocking of freight or metallic packaging materials. After several discussions and benchmarking of other, similar cases, CJ-GLS installed a conveyor belt system, with RFID antennas attached directly above the belt. Freight is placed on the belt individually and transported into the warehouse after being removed from their pallets and packaging materials, which block RFID frequencies. This business process reengineering enabled the RFID antennas to receive the information sent by RFID tags without any failures.

\subsubsection{Success factors}

The success factors of CJ-GLS's ubiquitous-oriented, RFID 3PL system showed how the company supports complementary assets [25-27], such as cultivating the organizational learning culture and managerial advancement, in addition to new technological innovations to achieve a competitive advantage against leading competitors.

4.4.2.1. A venture into the Blue Ocean: a highly motivated information strategy team culture. CJ-GLS realized IS as one of its core competencies early on. They developed and operated their core IS in-house, mobilized TPS, and recognized that the potential impact of ubiquitous technology and an information strategy team is the center for developing a successful IS. Highly motivated team members and a progressive culture within the information strategic team is the driving force.

CIO: We all agreed that RFID technology would be a solution to many logistics problems. However, we could not find a single successful case of RFID application in the logistics industry, and the RFID system vendors were not able to provide any useful application insights. We found that Wal-Mart and Tesco, just like us, are in the process of applying RFID technology to their logistics system and testing it. Instead of searching for and adopting prior applications, we (the information strategy team at CJ-GLS) chose to develop an RFID logistics 
system of our own with collaboration from outsourced research institutions. All team members of CJ-GLS and the researchers searched, shared, and learned RFID references, which later turned into a learning and proactive culture.

Even though we have no experience in this field, we are highly motivated to move in a new direction. The team members' attitude and CJ-GLS's culture is the driving force for individual and organizational growth.

4.4.2.2. Advantages of the first mover and top management leadership. In a global e-business environment, leadership is the driving force behind the revolution of the entire organization. While accomplishing the RFID-based, ubiquitous-oriented 3PL system project, top management at CJ-GLS manages participants consistently to prevent them from losing focus with the objectives of the project, which is highly possible when multiple participants are involved.

CJ-GLS logistics strategy research manager: This RFID project was our first large scale consortium. Therefore, we have less experience in collaborating with outside participants. Since all participants have their own interests in regards to the project, it was not an easy job to reconcile them to focus on the objectives. Our top management played an important role as a neutral consultant for moving the project in the right direction.

\subsubsection{Open mind-set for new ICT. CJ-GLS was} aware of the importance of the RFID-based, ubiquitous-oriented 3PL system and started research on technology by establishing a RFID center. The research initiative is located in the same physical space occupied by the information strategy team for easy communication among researchers and employees.

CIO: Our core competencies are not from the number of vehicles or warehouses but from a Koreanstyle, 3PL system development capability, top management's open mind to new technological innovations, and the system development capabilities of our human resources.

\section{Conclusion}

This case shows how a 3PL provider developed an ubiquitous, electronic logistics business model that pioneered into an uncontested market by not only defining customers from an existing logistics market but also by recognizing future customers.

Unlike numerous companies that have tried to mingle foreign solutions into their IS and business processes, CJ-GLS developed their own systems, managed the organizational changes, and utilized ICT's impact toward strengthening its 3PL business model. CJ-GLS evolved from an e-business supporting LIS to a m-business supporting ubiquitous-oriented LIS, which achieved efficiency in OMS and TPS. Whenever they faced bottlenecks and problems, they overcame those problems through organizational and technological change. When inefficiencies occurred from the existing business process, new technology was deployed. Once a new business process is enabled by technology, employees are educated and organizational changes follow.

CJ-GLS has built its competitive advantage through expanding capabilities, such as human resources and new technological innovations, rather than an expansion of tangible assets, such as warehouses and freight fleets, and has focused on its core competency, as well as strengthening its competitive advantage through utilizing technological innovation.

Because expansion of global e-business has brought about infinite global competition, companies must devote themselves to finding a new growth engine. Under these circumstances, the Blue Ocean strategy provides a guideline for how companies can survive by creating new, uncontested market space instead of competing in the existing market. CJ-GLS is an ongoing project and will continue until late 2007 or early 2008. We will continue this research by monitoring the future progress of this project.

\section{Acknowledgements}

The authors thank Dr. Angappa Gunasekaran and three anonymous referees for Omega for their helpful comments on earlier drafts of the paper. All errors are those of the authors.

\section{Appendix A.}

\section{A.1. Simple cost-benefit analysis}

Among the RFID-based, ubiquitous third-party logistics systems currently being developed by CJ-GLS, the cost incurred for the development of WMS was approximately $\$ 3$ million. Out of this amount, \$2.5 million was invested in software development, and the remaining \$0.5 million was spent on hardware development.

Compared to the existing bar code method, the RFIDbased WMS reduced the inspection time of logistics handling by $70-80 \%$. For instance, it took about four hours to process a palette of 100,000 boxes using the bar code method; on the other hand, it took only around $30 \mathrm{~min}$ using the RFID-based WMS. 
Table A1. Required process time and maximum quantity of goods handled

\begin{tabular}{lrr}
\hline & Bar code LIS & RFID LIS \\
\hline Receiving RFID frequency (s) & - & 300 \\
Stocking time (s) & 10 & 3 \\
In-storage handling time (s) & 600 & 3 \\
Picking/shipping inspection time (s) & 10 & 3 \\
Maximum quantity of goods & & \\
handled (units) & 139.35 & $279.61^{\mathrm{a}}$ \\
\hline
\end{tabular}

a Warehouse runs $24 \mathrm{~h}$ (84 $200 \mathrm{~s})$, and this operation hour is divided by process time of bar code LIS (620 s) and RFID LIS (309 s).

However, it is difficult to translate the timesaving into costs, as the cost of a bar code is 0.5 cent, whereas the cost of a RFID tag is 20-30 cents, and it is very expensive to develop readers, middleware, and other software that comprise the WMS. Moreover, it is difficult to make an accurate cost-benefit analysis as manpower is reduced due to the fact that the operation of the RFID-based WMS is often allocated for other jobs. Therefore, we used the simple costbenefit analysis using the process time and the quantity of goods handled in the bar code LIS and RFID LIS. Table A1 shows the detail information.

CJ-GLS estimates each unit generates $\$ 20$ of profit, and the gap of the average number of units daily processed between the bar code LIS and RFID LIS makes a difference of $\$ 2785.23$. ${ }^{3}$ If we only consider the simple cost and benefit analysis, the total implementation cost of $\$ 3$ million will be recovered within 1078 days, which is less than three years. CJ-GLS wants to gain strategic advantages using RFID.

\section{References}

[1] W. C. Kim and R. Mauborgne, Blue ocean strategy: from theory to practice, California Management Review 47 (3) (2005), pp. 105-121.

[2] H. Bhise, D. Farrell, H. Miller, A. Vanier, and A. Zainulbhai, The duel for the doorstep, The McKinsey Quarterly 2 (2000), pp. 33-41.

[3] H. L. Lee and S. Whang, Winning the last mile of e-commerce, MIT Sloan Management Review 42 (4) (2001), pp. 54-63.

[4] W. B. Lee and H. C. W. Lau, Factory on demand: the shaping of an agile production network, International Journal of Agile Management Systems 1 (2) (1999), pp. 83-87.

[5] D. Simchi-Levi, J. Bramel, and X. Chen, The logic of logistics: theory, algorithms, and applications for logistics and supply chain management, Springer, New York (2004).

[6] E. Rabinovich, R. Windle, M. Dresner, and T. Corci, Outsourcing of integrated logistics functions, International Journal of Physical Distribution and Logistics Management 29 (6) (1999), pp. 353-373.

[7] H. L. Sink and C. J. Langley, A managerial framework for the acquisition of third-party logistics services, Journal of Business Logistics 19 (1) (1997), pp. 121-136.

\footnotetext{
3 \$3 million is divided by $(279.61-139.35) \times \$ 20$.
}

[8] T. Kimura, The emergence of third party logistics, NLI Research Institute, Tokyo, Japan (1998) p. 120.

[9] G. Vaidyanathan, A framework for evaluating third-party logistics, Communications of the ACM 48 (1) (2005), pp. 89-94.

[10] D. W. Krumwiede and C. Sheu, A model for reverse logistics entry by third party provides, Omega 30 (5) (2002), pp. 325-333.

[11] L. K. Bruckner and T. Kiss, Grid solution for e-marketplaces integrated with logistics. In: Conference proceedings of the DAPSYS 2004 conference, Budapest, Hungary, September 1922, 2004.

[12] L. M. Sjöstedt, Managing sustainable mobility: a conceptual framework. In: B. Tilanus, Editor, Information systems in logistics and transportation, Elsevier Science Ltd., Kidlington, Oxfordshire (2002), pp. 19-31.

[13] N. Carr, IT doesn't matter, Harvard Business Review 81 (5) (2003), pp. 41-49.

[14] S. Hsi and H. Fait, RFID enhances visitors' museum experience at the exploratorium, Communications of the ACM 48 (9) (2005), pp. 60-65.

[15] J. Singh, N. Brar, and C. Fong, The state of RFID applications in libraries, Information Technology Libraries 25 (1) (2006), pp. 24-32.

[16] B. Janz, M. Pitts, and R. Otondo, Information systems and health care II: back to the future with RFID: lessons learned - some old, some new, Communications of the Association for Information Systems 15 (2005), pp. 132-148.

[17] J. Yagi, E. Arai, and T. Arai, Parts and packets unification radio frequency identification (RFID) application for construction, Automation in Construction 14 (4) (2005), pp. 477-490.

[18] G. Y. Tütüncü, C. A. C. Carreto, and B. M. Baker, A visual interactive approach to classical and mixed vehicle routing problems with backhauls, Omega 36 (2008, in press), doi: 10.1016/j.omega.2006.11.001.

[19] Z. Hua and S. Li, Impacts of demand uncertainty on retailer's dominance and manufacturer-retailer supply chain cooperation, Omega 36 (2008, in press), doi: 10.1016/j.omega.2006.02.005.

[20] J. Blackhurst, T. Wu, and C. W. Craighead, A systematic approach for supply chain conflict detection with a hierarchical Petri Net extension, Omega 36 (2008, in press), doi: 10.1016/j.omega.2006.02.001.

[21] D. Ding and J. Chen, Coordinating a three level supply chain with flexible return policies, Omega 36 (2008, in press), doi: 10.1016/j.omega.2006.04.004.

[22] N. R. Sanders and G. A. Graman, Quantifying costs of forecast errors: a case study of the warehouse environment. Omega 36 (2008, in press), doi: 10.1016/j.omega.2006.10.004.

[23] Y. Chen, C. Wang, and S. Lin, A multi-objective geographic information system for route selection of nuclear waste transport. Omega 36(3) (2008), pp. 363-72.

[24] W.C. Kim and R. Mauborgne, Blue Ocean strategy: how to create uncontested market space and make competition irrelevant, Harvard Business School Press, Boston (2004).

[25] E. Brynjolfsson and L.M. Hitt, Beyond computation: information technology, organizational transformation, and business performance, Journal of Economic Perspectives 14 (4) (2000), pp. 23-48.

[26] D.A. Marchand, Extracting the business value of IT: it is usage, not just deployment that counts, Journal of Financial Transformation 11 (2004), pp. 125-131.

[27] D. Teece, Economic performance and theory of the firm: the selected papers of Daivd Teece, Edward Elgar Publishing, London (1998). 